\title{
Relation between immediate postpartum APGAR score with umblical cord blood pH and fetal distress
}

\author{
Varuna Pathak ${ }^{1}$, Deep Shikha Sahu ${ }^{2 *}$
}

\begin{abstract}
${ }^{1}$ Department of Obstetrics and Gynecology, Gandhi Medical College, Bhopal, Madhya Pradesh, India
${ }^{2}$ Department of Obstetrics and Gynecology, Bundelkhand Medical College, Sagar, Madhya Pradesh, India
\end{abstract}

Received: 24 October 2019

Revised: 30 October 2019

Accepted: 04 November 2019

\section{*Correspondence:}

Dr. Deep Shikha Sahu,

E-mail: drshikha991990@gmail.com

Copyright: () the author(s), publisher and licensee Medip Academy. This is an open-access article distributed under the terms of the Creative Commons Attribution Non-Commercial License, which permits unrestricted non-commercial use, distribution, and reproduction in any medium, provided the original work is properly cited.

\begin{abstract}
Background: The one-minute Apgar score, proven useful for rapid assessment of the neonate, is often poorly correlated with other indicators of intrauterine well-being. Fetal asphyxia is directly associated with neonatal acidosis. Umbilical cord $\mathrm{pH}$ is best indicator of fetal hypoxemia and hypoxemia leads to neonatal acidosis. In today scenario, fetal distress is the leading indication of emergency cesarean section.

Methods: A observational cross-sectional study conducted of one year between march 2017 to February 2018; of full-term obstetric patients undergoing emergency cesarean section for fetal distress as an indication. All patients included are term gestation with low risk pregnancy excluding medical disorders and other complications of pregnancy. Immediately after delivery umbilical artertial cord blood from placental site collected and sent for $\mathrm{pH}$ determination and Apgar score calculated of newborn.

Results: Emergency cesarean section was being done for fetal distress diagnosed based on guidelines for Intermittent auscultation; maximum patients had fetal bradycardia (240) followed by fetal tachycardia (12) and irregular rhythm (18). Relation between $\mathrm{pH}$ value and the fetal outcome babies who had low $\mathrm{pH}$ value. i.e. <7.1; had maximum referrals with poor Apgar score at $1 \mathrm{~min}(<3)$ and at $5 \min (<3)$. Out of 270 babies 18 had Apgar score $<3$ at 1 min, out of which 10 continued to have Apgar score $<3$ at 5 mins. These babies were referred to department of pediatrics and were not alive beyond day 2-4.

Conclusions: The values of mean Apgar score and cord blood $\mathrm{pH}$ decreases, which is inversely proportion to duration and severity of intrauterine/intra partum asphyxia. Umbilical arterial cord blood $\mathrm{pH}$ correlation was found to be significant with Apgar score in neonates delivered with indication as fetal distress.
\end{abstract}

Keywords: Apgar score, Cesarean section, Fetal distress, Umbilical cord blood pH

\section{INTRODUCTION}

Current trends of increasing cesarean section rate in last few decades and among primigravida's most common indication has been fetal distress. To justify the indication and with future prospects of neonatal outcome; umbilical arterial cord blood $\mathrm{pH}$ is an important and relevant indicator among others. Fetal distress as being commonest indication; the immediate neonatal outcome is assessed by APGAR score. Fetal distress has been described as "a condition in which fetal physiology is so altered to make death or permanent injury a probability within a relatively short period of time and usually considered to denote disruption of normal fetal 
oxygenation, ranging from mild hypoxia to profound fetal asphyxia". ${ }^{1}$ Considerable studies have been done to determine risk factors and role of intrapartum asphyxia causing adverse neonatal outcomes in infants delivered at term. ${ }^{2}$ The aim of fetal surveillance is to identify fetuses at risk for neonatal and long-term injury due to asphyxia and to prevent morbidity and mortality. Routine tools of intrapartum fetal surveillance are intermittent fetal heart auscultation, observation for MSAF, cardiotocography and fetal scalp blood sampling. ${ }^{3}$ Intermittent auscultation (IA) is defined as the technique of listening to the fetal heart rate (FHR) for short periods of time without a display of the resulting pattern. Whether it be used for intrapartum fetal monitoring in low-risk women, all healthcare professionals attending labor and delivery need to be skilled at performing IA, interpreting its findings, and taking appropriate action. ${ }^{4-7}$ In general, the progression from well oxygenated to acidemia takes approximately one hour. ${ }^{8}$ Alternatively, acute hypoxic events that do not resolve will be evident as acute fetal bradycardia. Thus, FHR characteristics detectable via EFM or IA must be interpreted with regard to their accompanying risk for the presence of fetal academia. After birth foetal asphyxia is subjectively assessed by Apgar score and objectively by cord blood $\mathrm{pH}$ and lactate levels. Arterial and venous cord blood gases provide evidence of fetal and placental oxygenation at birth. In accordance with the SOGC "Attendance at Labour and Delivery Guidelines," arterial and venous cord blood gas analysis is recommended routinely for all births, as they may help in providing appropriate care to the new-born at birth and in planning subsequent management. ${ }^{9}$ There was also a significant relation between umbilical cord $\mathrm{pH}$ and low Apgar score with the incidence of selective neonatal outcomes like neonatal intensive care unit (NICU) admission and need for advanced resuscitation. ${ }^{10}$ Metabolic acidosis in umbilical cord arterial blood at birth is commonly defined as $\mathrm{pH}<7.00$ (or <7.05) and base deficit $(\mathrm{BD}) \geq 12.0 \mathrm{mmol} / \mathrm{L}$. $^{11}$ There is a growing attitude for using umbilical cord blood gas (UCBG) analysis on all deliveries to have an idea of neonatal status and to know even if the fetus has been exposed to hypoxia and to justify the indication of emergency cesarean section as fetal distress. ${ }^{12}$

\section{METHODS}

An observational cross-sectional study was conducted among 270 admitted patients in emergency and had been taken for cesarean section in department of obstetrics and gynaecology, Gandhi Medical College Bhopal. All pregnant patients that were meeting the inclusion criteria and giving consent were recruited. Study period was between March 2017 to February 2018.

\section{Inclusion criteria}

- Patient giving informed consent

- Cesarean section with the indication as fetal distress
- Gestational age of $\geq 37$ weeks (completed) from the last menstrual period or first trimester scan

- The pregnancy must be singleton with cephalic presentation and longitudinal lie.

\section{Exclusion criteria}

- Cesarean section done for other than fetal distress as indications

- Gestational weeks below 37 weeks

- Mal-presentations

- Multiple gestations

- All high risks pregnancy (anemia, hypertension, thyroid disorders, diabetes, epilepsy, asthma)

- Elective cesarean sections.

After explaining objectives of the study to the study subjects and obtained written consent (from the caregivers in case the patient is unresponsive). Variables related to demographic characteristics and study objectives was entered, compiled in Microsoft excel 2007. Patient data was collected in a pre-designed format and questionnaire. After patient had been posted for emergency caesarean section, blood collection was performed, from immediately isolated segment (10 to 20 $\mathrm{cm}$ ) of cord with two clamps near the neonate two clamps nearer the placenta. The importance of clamping the cord is underscored by the fact that delays of 20-30 secs can alter both the $\mathrm{PCO}_{2}$ and $\mathrm{pH}$. The cord was then cut between the two proximal and two distal clamps. Arterial blood was drawn from the isolated segment of cord into a $2 \mathrm{ml}$ syringe that are pre heparinized lithium syringes. The needle was capped and the syringe transported on ice to the laboratory. Neonate was handed over to paediatrician and Apgar score was recorded at $1 \mathrm{~min}$ and $5 \mathrm{~min}$.

\section{Statistical analysis}

Collected data was checked for its completeness and correctness before analysis. Data was finally tabulated, analyzed and interpreted by using appropriate inferential statistical tests. This was analyzed using Epi Info ${ }^{\text {TM }}$ 7.1.5 and SPSS 20.0 (free trial version).

\section{RESULTS}

Table 1: Demonstrates distribution of study subjects according to fetal heart rate pattern.

\begin{tabular}{|lll|}
\hline Fetal heart rate & Number & Percentage $(\%)$ \\
\hline Bradycardia & 240 & 88.9 \\
\hline Tachycardia & 12 & 4.4 \\
\hline Irregular heart rate & 18 & 6.7 \\
\hline Total & $\mathbf{2 7 0}$ & $\mathbf{1 0 0}$ \\
\hline
\end{tabular}

This study was done in department of obstetrics and gynaecology, Gandhi Medical College Bhopal between March 2017 to February 2018. Total 270 patients were 
enrolled who were diagnosed with fetal distress via intermittent auscultation and underwent emergency cesarean section. Data collected in preformed format and umbilical cord blood collected from placental end; immediately following delivery. ABG analysis done within 40 mins of collection.

Table 2: Depicts comparison between fetal distress grading with the Apgar score at 1 minute and 5 minutes.

\begin{tabular}{|lllll|}
\hline Grading of fetal distress & Bradycardia & Tachycardia & Irregular heart rate & Total \\
\hline APGAR score at 1 min & & & & \\
\hline $7-10$ & $0(0.0 \%)$ & $0(0.0 \%)$ & $0(0.0 \%)$ & $0(0.0 \%)$ \\
\hline $4-6$ & $240(88.9 \%)$ & $12(4.4 \%)$ & $0(0.0 \%)$ & $252(93.3 \%)$ \\
\hline$<3$ & $0(0.0 \%)$ & $0(0.0 \%)$ & $18(6.7 \%)$ & $18(6.7 \%)$ \\
\hline APGAR Score at 5 min & & & & \\
\hline 7-10 & $200(74.1 \%)$ & $8(3.0 \%)$ & $0(0.0 \%)$ & $208(77.0 \%)$ \\
\hline $4-6$ & $40(14.8 \%)$ & $4(1.5 \%)$ & $8(6.7 \%)$ & $62(23.0 \%)$ \\
\hline$<3$ & $0(0.0 \%)$ & $0(0.0 \%)$ & $10(3.7 \%)$ & $10(3.7)$ \\
\hline Total & $240(88.9 \%)$ & $12(4.4 \%)$ & $18(6.7 \%)$ & $270(100 \%)$ \\
\hline
\end{tabular}

Chi square value found to be 270 and 'p' value was 0.001 which is highly significant

Table 3: Compares pH of umbilical arterial cord blood of patients operated with indication as fetal distress with Apgar score at 1 minute and 5 minutes.

\begin{tabular}{|c|c|c|c|c|}
\hline \multicolumn{5}{|c|}{ pH of umbilical arterial cord blood } \\
\hline Apgar score at $1 \mathrm{~min}$ & $<7.1$ & 7.1-7.3 & $>7.3$ & Total \\
\hline $7-10$ & $0(0.0 \%)$ & $0(0.0 \%)$ & $0(0.0 \%)$ & $0(0.0 \%)$ \\
\hline $4-6$ & $2(0.7 \%)$ & $213(78.9 \%)$ & $37(13.8 \%)$ & $252(93.4 \%)$ \\
\hline$\leq 3$ & $12(4.4 \%)$ & $6(2.2 \%)$ & $0(0.0 \%)$ & $18(6.6 \%)$ \\
\hline \multicolumn{5}{|c|}{ pH of umbilical arterial cord blood } \\
\hline Apgar score at $5 \mathrm{~min}$ & $<7.1$ & 7.1-7.3 & $>7.3$ & Total \\
\hline $7-10$ & $2(0.7 \%)$ & $176(65.2 \%)$ & $27(10.0 \%)$ & $205(75.9 \%)$ \\
\hline $4-6$ & $5(1.8 \%)$ & $43(15.9 \%)$ & $10(3.8 \%)$ & $58(21.5 \%)$ \\
\hline$\leq 3$ & $7(2.6 \%)$ & $0(0.0 \%)$ & $0(0.0 \%)$ & $7(2.6 \%)$ \\
\hline Total & $14(5.2 \%)$ & $219(81.1 \%)$ & $37(13.7 \%)$ & $270(100.0 \%)$ \\
\hline
\end{tabular}

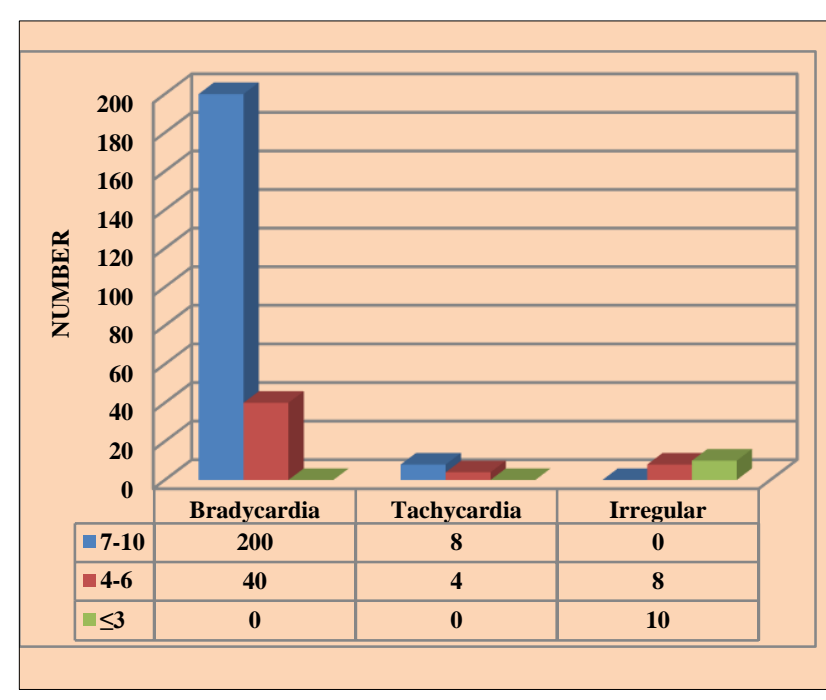

Figure 1: Distribution of study subjects according to severity of fetal distress and Apgar score at 1 and 5 minutes.

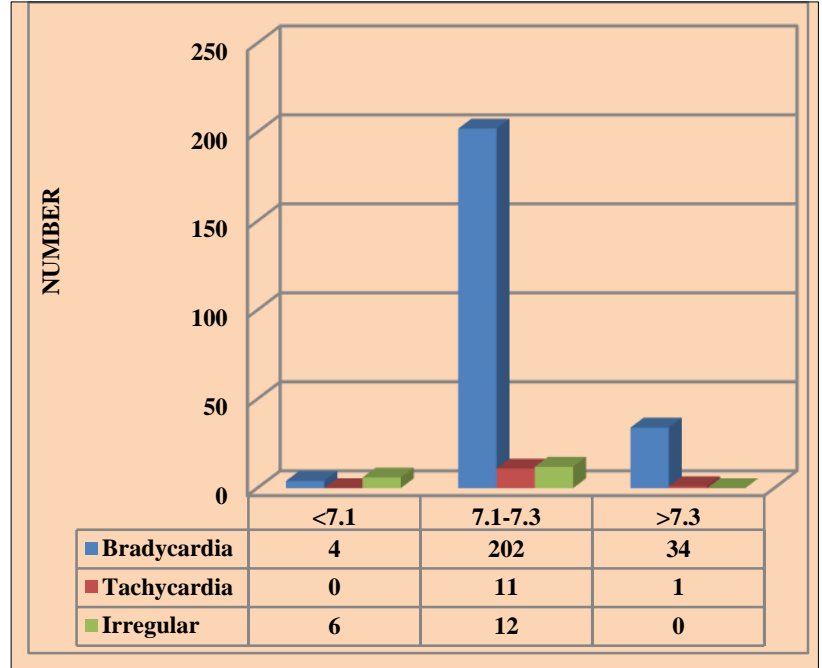

Figure 2: Distribution of study subjects according to severity of fetal distress and $\mathrm{pH}$ of cord blood. 
Among 270 patients, that were taken for emergency cesarean section with indication as fetal distress; maximum $(88.9 \%)$ had bradycardia and 18 patients had irregular heart rate $(6.7 \%)$. This shows the distribution of pregnant patients according to fetal heart pattern heard via intermittent auscultation method (Table 1).

Table 2 reveals distribution of study subjects according to severity of fetal distress and Apgar score at 1 and 5 minutes. At 1-minute Apgar score 7-10 was not found in anyone, $252(93.3 \%)$ had 4-6 and $18(6.7 \%)$ had less than 3 score. After 5-minute Apgar score was increased and $208(77.0 \%)$ had 7-10 Apgar score and only $10(3.7 \%)$ had less than 3 score. There was statistically significant difference found in distribution of study subjects according to severity of fetal distress and Apgar score at 1 and 5 minutes $(\mathrm{p}=0.001)$ (Table $2 /$ Figure 1$)$. As authors had discussed earlier, there was significant relation found between grading of fetal distress and $\mathrm{pH}$ of umbilical arterial cord blood. 235(87.03\%) new-born babies had $\mathrm{pH}<7.3$ i.e. neonatal acidosis was found and these babies had fetal distress. Most common patients had bradycardia (76.29\%) diagnosed and taken for cesarean section Figure 2.

In above figures we could conclude that Apgar score correlated well with $\mathrm{pH}$ of umbilical arterial cord blood, 213 (78.88\%) new-born babies had $\mathrm{pH}$ between 7.1-7.3 and Apgar score at $1 \mathrm{~min}$ between 4-6. Out of these 213; $43(15.9 \%)$ babies still had Apgar score between 4-6. We can also find that new-born who had $\mathrm{pH}<7.1$. i.e. 14 (5.2\%) had poor Apgar also. Chi square found to be 48.857 at Apgar $1 \mathrm{~min}$ and 8.092 at Apgar 5 min. 'P' value found to be 0.001 which is highly significant Table 3.

\section{Table 4: Demonstrates relation between $\mathrm{pH}$ value of umbilical cord blood of new-born babies with indication as fetal distress to NICU (neonatal ICU) admissions.}

\begin{tabular}{|lll|}
\hline pH Value & NICU admission (20) & Neo-death \\
\hline$<7.1$ & 14 & 10 \\
\hline $7.1-7.3$ & 6 & 4 \\
\hline$>7.3$ & 0 & 0 \\
\hline Total & 20 & 14 \\
\hline
\end{tabular}

Reveals distribution of study subjects according to umbilical arterial cord blood $\mathrm{pH}$ and NICU admission. Among 270 babies, $\mathrm{pH}<7.1$ was depicted in 14 babies; out of which 10 were neo-death and 06 babies who had their $\mathrm{pH}$ value between 7.1-7.3 admitted in NICU; only 2 reverted back to their mother. This was found to be statistically significant. 14 new-borns who had poor Apgar score and low pH were neo-death Table 4.

\section{DISCUSSION}

This study aims to justify the ever-increasing rate of caesarean section for indication of fetal distress and relationship between the $\mathrm{pH}$ value of umbilical arterial cord blood and Apgar score of new-borns. Based on guidelines for intermittent auscultation, maximum 240 patients had fetal bradycardia $(88.9 \%)$ followed by fetal tachycardia (12) and 18 study subjects had irregular rhythm (6.7\%). Although irregular rhythm had a poor prognosis based on umbilical cord blood $\mathrm{pH}$ and Apgar score. As per Apgar grading; no newborn baby had good Apgar score i.e. $>7$ at 1 minute but after 5 minutes; 208 newborn subjects had good Apgar score while out of 72 newborns still had bad Apgar score. Also, Babies who had poor Apgar score; had low $\mathrm{pH}$ value $<7.3$ tested via umbilical cord blood $\mathrm{pH}$. These babies could have neural pathology or cerebral palsy in nearby future and will justify the indication of emergency cesarean section with its increasing rate.

We could conclude that patients who were diagnosed as fetal distress and undergone emergency ceasarean section had low $\mathrm{pH}$ values of umbilical cord blood and poor Apgar score with NICU admission; with 14 neo-deaths within 7 days of delivery. Similar, findings were found in some studies. Perveen F et al, also had similar results "Significance of cord arterial blood $\mathrm{pH}$ as a predictor of intrapartum hypoxia is considerable in determining neonatal outcome but at $\mathrm{pH}$ level $>7.1$ the neonatal neurologic morbidity is not so evident. Although moderate degree of acidemia $<7.1$ is associated with increased risk of adverse neonatal outcome, the absolute risks are very low and most affected babies have a higher $\mathrm{pH}$ than this as evident in this study."13

Meena $\mathrm{P}$ et al, also stated that "It was noted that as the severity of HIE increases, the values of mean Apgar score and cord blood $\mathrm{pH}$ decreases, which is inversely proportion to duration and severity of intrauterine/intra partum asphyxia. ${ }^{14}$ Lower umbilical cord blood $\mathrm{pH}$ is also associated with unfavourable immediate outcome in terms neurological abnormalities and poor final outcome in terms of death at the time of discharge."

Also, Goldaber et al, who studied the association between umbilical arterial acidosis and adverse neurological events among 3506 term, singleton infants with cord arterial $\mathrm{pH}<7.20 .18$; reported that the neonatal death was much more likely at $\mathrm{pH}<7.00$, the cut-off at which seizures became more likely was $\mathrm{pH}<7.05$, and for unexplained seizures was $\mathrm{pH}<7$. $^{15}$

\section{CONCLUSION}

The present study reveals that fetal tachycardia, bradycardia and irregular heart rate found on intermittent low risk singleton term pregnancy were associated with fetal acidosis and poor neonatal outcome. We concluded that the when umbilical cord blood $\mathrm{pH}$ is available at birth it is a better marker of perinatal asphyxia. As the duration and severity of asphyxia increases it will further decrease the cord blood $\mathrm{pH}$. Cord blood $\mathrm{pH}$ can be used to predict the severity and outcome of birth asphyxia in 
new-borns in addition to Apgar score. There was significant relation between Apgar score and $\mathrm{pH}$ of cord blood in fetal distress new-borns.

\section{ACKNOWLEDGMENTS}

Authors would like to say no words, no gesture can ever express my gratitude towards Dr. Sameer Singh, whose efforts, support and constant help made this thesis a wonderful research work by providing me acid base gas analyser radiometer ABL system 600.

Funding: No funding sources Conflict of interest: None declared

Ethical approval: The study was approved by the Institutional Ethics Committee

\section{REFERENCES}

1. Tasnim N, Mahmud G, Akram S. Predictive accuracy of intrapartum cardiotocography in terms of fetal acid base status at birth. J Coll Physicians Surg Pak. 2009;19(10):632-5.

2. Malin GL, Morris RK, Kha KS. Strength of association between umbilical cord $\mathrm{pH}$ and perinatal and long-term outcomes: systematic review and metaanalysis. BMJ. 2010;340:c1471.

3. Parveen S. Umbilical cord arterial blood base excess as gold standard for foetal well-being screening test validity at term delivery. J Pak Med Assoc. 2010;60(5):347-50.

4. American College of Obstetricians and Gynecologists. Practice bulletin no. 116: management of intrapartum fetal heart rate tracings. Obstet Gynecol. 2010;116(5):1232-40.

5. Lyndon A, Ali LU, eds. Fetal heart monitoring principles and practices. $4^{\text {th }}$ ed. Dubuque, IA: Kendall-Hunt Publishing Company; 2009.

6. Liston R, Sawchuck D, Young D. Society of obstetrics and gynaecologists of Canada, British Columbia Perinatal Health Program. Fetal health surveillance: antepartum and intrapartum consensus guideline. J Obstet Gynaecol Can. 2007;29(9 Suppl 4):S3-S56.
7. National Institute for Health and Care Excellence. Intrapartum care of healthy women and their babies during childbirth. Available at: http://www.nice.org.uk/guidance/cg55. Accessed on $11^{\text {th }}$ November 2014.

8. Williams KP, Singh A. The correlation of seizures in newborn infants with significant acidosis at birth with umbilical artery cord gas values. Obstet Gynecol. 2002;100(3):557-60.

9. Executive Committee of the Society of Obstetricians and Gynecologists of Canada. Attendance at labour and delivery: guidelines for obstetrical care. SOGC Policy Statement No. 89, May 2000. J Soc Obstet Gynaecol Can. 2000;22:389-91.

10. Ahmadpour-Kacho M, Asnafi N, Javadian M, Hajiahmadi M, Taleghani N. Correlation between umbilical cord $\mathrm{pH}$ and Apgar score in high-risk pregnancy. Iran J Pediatr. 2010;20(4):401-6.

11. The report of ACOG's task force on neonatal encephalopathy and cerebral palsy has been published. Neonatal Encephalopathy and Cerebral Palsy: Execut Sum Obstet Gynecol. 2004;103(4):780-1.

12. Tong S, Egan V, Griffin J, Wallace EM. Cord blood sampling at delivery: do we need to always collect from both vessels? BJOG. 2002;109(10):1175-7.

13. Perveen F, Khan A. Umbilical cord blood $\mathrm{pH}$ in intrapartum hypoxia. J College Phys Surg Pak. 2015;25(9):667-70.

14. Meena P, Meena M, Gunawat M. Correlation of APGAR score and cord blood $\mathrm{pH}$ with severity of birth asphyxia and short-term outcome. Int $\mathbf{J}$ Contemp Pediatr. 2017;4:1325-8.

15. Goldaber KG, Leveno KJ, Gilstrap LC, Dax JS, McIntire DD. Pathologic fetal acidemia. Obstet Gynecol. 1991;78(6):1103-7.

Cite this article as: Pathak V, Sahu DS. Relation between immediate postpartum APGAR score with umblical cord blood $\mathrm{pH}$ and fetal distress. Int J Reprod Contracept Obstet Gynecol 2019;8:4690-4. 